\title{
End-of-life care preferences of the general public and recommendations of healthcare providers: a nationwide survey in Japan
}

\author{
Jun Hamano ${ }^{1 *}$, Kyoko Hanari ${ }^{2}$ and Nanako Tamiya ${ }^{3}$
}

\begin{abstract}
Background: A better understanding of differences between the preferences of the general public and the recommendations of healthcare providers with regard to end-of-life (EOL) care may facilitate EOL discussion.

Methods: The aim of this study was to clarify differences between preferences of the general public and recommendations of healthcare providers with regard to treatment, EOL care, and life-sustaining treatment (LST) based on a hypothetical scenario involving a patient with advanced cancer. This study comprised exploratory post-hoc analyses of "The Survey of Public Attitude Towards Medical Care at the End of life", which was a population based, cross-sectional anonymous survey in Japan to investigate public attitudes toward medical care at the end of life. Persons living in Japan over 20 years old were randomly selected nationwide. Physicians, nurses, and care staff were recruited at randomly selected facilities throughout Japan. The general public data from the original study was combined to the data of healthcare providers in order to conduct exploratory post-hoc analyses. The preferences of the general public and recommendations of healthcare providers with regard to EOL care and LST was assessed based on the hypothetical scenario of an advanced cancer patient.
\end{abstract}

Results: All returned questionnaires were analyzed: 973 from the general public, 1039 from physicians, 1854 from nurses, and 752 from care staff (response rates of 16.2, 23.1, 30.9, and 37.6\%, respectively). The proportion of the general public who wanted "chemotherapy or radiation", "ventilation", and "cardiopulmonary resuscitation" was significantly higher than the frequency of these options being recommended by physicians, nurses, and care staff, but the general public preference for "cardiopulmonary resuscitation" was significantly lower than the frequency of its recommendation by care staff.

Conclusion: Regarding a hypothetical scenario for advanced cancer, the general public preferred more aggressive treatment and more frequent LST than that recommended by healthcare providers.

Keywords: End-of-life care, General public, Advanced cancer patient, Life-sustaining treatment, Nationwide survey, Hypothetical scenario

\footnotetext{
* Correspondence: junhamano@md.tsukuba.ac.jp

'Division of Clinical Medicine, Faculty of Medicine, University of Tsukuba,

1-1-1 Tennoudai, Tsukuba 305-8575, Ibaraki, Japan

Full list of author information is available at the end of the article
}

C C The Author(s). 2020 Open Access This article is licensed under a Creative Commons Attribution 4.0 International License, which permits use, sharing, adaptation, distribution and reproduction in any medium or format, as long as you give appropriate credit to the original author(s) and the source, provide a link to the Creative Commons licence, and indicate if changes were made. The images or other third party material in this article are included in the article's Creative Commons licence, unless indicated otherwise in a credit line to the material. If material is not included in the article's Creative Commons licence and your intended use is not permitted by statutory regulation or exceeds the permitted use, you will need to obtain permission directly from the copyright holder. To view a copy of this licence, visit http://creativecommons.org/licenses/by/4.0/ The Creative Commons Public Domain Dedication waiver (http://creativecommons.org/publicdomain/zero/1.0/) applies to the data made available in this article, unless otherwise stated in a credit line to the data. 


\section{Key message}

This nationwide cross-sectional survey investigated the preferences of the general public and recommendations of healthcare providers regarding end-of-life care based on the hypothetical scenario of an advanced cancer patient. The general public was found to prefer more aggressive treatment and more frequent life-sustaining treatment than that recommended by healthcare providers.

\section{Background}

Personalized end-of-life (EOL) care is required for patients and their families to achieve a high-quality end of life [1], but $40-79 \%$ of terminally ill patients cannot express their own goals and preferences for medical treatment/care due to physical deterioration or mental incapacity [2-5]. Recent systematic reviews suggested that advanced care planning increases discussion about future treatment and EOL care, improves the quality of communication between patient and healthcare providers, and improves correspondence of the care provided with patient preferences in many patient populations $[6,7]$.

A recent international recommendation on advance care planning pointed out that involving multidisciplinary healthcare providers, including nurses and care staff, to support discussion about patient preferences regarding the goals of care is an important part of the EOL care process $[8,9]$.

Another recent study revealed a discrepancy between patient preferences for EOL care, including lifesustaining treatment (LST), and physician recommendations on EOL care $[10,11]$, but it is unclear whether differences also exist between patients and nurses or care staff with an essential role in providing EOL care.

As decisions about EOL care are often difficult and involve a high degree of discretion on the part of the healthcare provider, it is important for providers to understand that there may be differences between patient preferences and their recommendations about EOL care and LST.

A recent longitudinal study reported that EOL care was discussed between physicians and $9.2-18.3 \%$ of terminal cancer patients, and these discussions only increased significantly in the last month of life [12]. Barrio-Cantalejo et al. reported that $86 \%$ of older persons did not change their preferences for EOL care and LST [13]. Therefore, it may be important to investigate the preferences of the general public with regard to EOL care and LST in order to facilitate EOL care discussions between healthcare providers and terminal cancer patients.

Therefore, this study aimed to clarify differences between preferences of the general public and recommendations of healthcare providers (physicians, nurses, and care staff) with regard to cancer treatment, EOL care, and LST based on a hypothetical scenario involving a patient with advanced cancer. The secondary objective was 1) to explore factors influencing the preferences of the general public and the recommendations of physicians, nurses and care staff regarding cancer treatment, EOL care, and LST, and 2) to clarify the differences in recommendations regarding cancer treatment, EOL care, and LST among healthcare providers.

\section{Methods}

\section{Participants and procedure}

The aim of this study was to clarify differences between preferences of the general public and recommendations of healthcare providers with regard to treatment, EOL care, and life-sustaining treatment (LST) based on a hypothetical scenario involving a patient with advanced cancer.

This study comprised exploratory post-hoc analyses of "The Survey of Public Attitude Towards Medical Care at the End of life", which was a population based, crosssectional anonymous survey to investigate public attitudes toward medical care at the end of life conducted descriptively by the Ministry of Health, Labour and Welfare (MHLW), Japan in December 2017.

The source population of the original study was members of the general Japanese public aged 20 and over. The stratified two-stage random sampling method was used for selection. The survey was administered by mail in questionnaire packs. In addition to the questionnaire, the packs sent out by post also included explanatory letters from the MHLW, and stamped, addressed envelopes to return the questionnaire.

The participants of this study were members of the general public, physicians, nurses, and care staff. We used the general public data from the original study, and combined it with the data of healthcare providers in order to conduct exploratory post-hoc analyses, though the original study was conducted just for description not for analysis by the government. The questionnaire was sent by mail to 6000 members of the general public, 4500 physicians, 6000 nurses, and 2000 care staff, accompanied by a letter that concisely explained the survey. The details on how to select target participant and facilities, and how to distribute the questionnaire were described in our previous study [14]. The MHLW sent a reminder to all non-responders in January 2018. Completion and return of the questionnaire, in combination with the explanatory letter, was considered to indicate voluntary and informed consent to participate. The institutional review board of the University of Tsukuba approved the protocol of this study.

\section{Questionnaire}

As there were no specific and validated instruments for evaluating the preferences of the general public and 
recommendations of healthcare providers regarding treatment, EOL care, and LST, we developed an original questionnaire based on data from previous studies [11, 15-17] and discussion among the authors of this study. Subsequently, we submitted the draft questionnaire to the MHLW and they made the final decision about the questionnaire items.

We used a scenario about a hypothetical cancer patient to investigate preferences for cancer treatment, EOL care, and LST based on the previous nationwide survey conducted in 2011 [15]. We submitted the draft questionnaire to the MHLW and they made the final decision about the questionnaire items. The respondents were asked to imagine that they were diagnosed with terminal cancer and going to die within 1 year (see Table 1), and were asked to express their preferences (or recommendations in the case of physicians, nurses, and care staff) about cancer treatment, EOL care, and LST. The treatments investigated were chemotherapy or radiation therapy for cancer (chemotherapy or radiation), fluid infusion if unable to drink water (fluid infusion), total parenteral nutrition (TPN) if unable to intake sufficient nutrition orally (TPN), nasogastric (NG) tube feeding if unable to intake sufficient nutrition orally (NG tube feeding), percutaneous endoscopic gastrostomy (PEG) tube feeding if unable to intake sufficient nutrition orally (PEG tube feeding), mechanical ventilation if it became difficult to breathe (ventilation), and cardiopulmonary resuscitation (CPR) if the heart or breathing stopped (CPR). The general public was asked to select from the following options: want treatment or care, do not want treatment or care, or not sure. For physicians, nurses, and care staff, the options were as follows: recommend treatment or care, do not recommend treatment or care, or not sure.

We collected the following background characteristics of the general public based on previous studies and discussion among the authors of this study: age in 5-year intervals from 20 to over 85 , gender, living status, education, family doctor, and death of a close person within 5 years $[11,15]$. We also collected the following background characteristics of the healthcare providers based on previous studies $[11,16,17]$ and discussion among the authors: years of practice, workplace, frequency of

\section{Table 1}

-Condition of the patient-

After the diagnosis of terminal cancer, the condition has worsened. It has become difficult to eat and breathing is difficult. However, there is no pain, and consciousness and judgment are maintained at the same level as when healthy.

-Medical judgment-

"There is no prospect of recovery, and death will occur gradually or suddenly within approximately 1 year." caring for dying patients, identifying the proxy decision maker as standard practice, and participation in a nationwide education program on EOL discussion (binary category) [Palliative Care Emphasis Program on Symptom Management and Assessment for Continuous Medical Education (PEACE) and/or Education For Implementing End-of-Life Discussion (E-FIELD) for healthcare providers] [18-20]. PEACE is a 2-day interactive education program for physicians that integrates palliative care and psycho-oncology. It has been available since 2007. E-FIELD is a 1- or 2-day interactive education program for healthcare providers about respecting the patient's wishes for EOL care and practicing based on the best interests of the patient, which has been held since 2016.

\section{Analysis}

We initially conducted descriptive analyses of categorical variables. We defined "chemotherapy or radiation" as aggressive cancer treatment, "fluid infusion", "NG", "TPN", and "PEG tube feeding" as EOL care, and "ventilation" and "CPR" as LST. We defined the answer "want/recommend treatment or care" as the preference for aggressive cancer treatment, EOL care and LST, and we defined "not sure" as missing data because it can be interpreted as both positive and negative opinions. We defined healthcare providers who answered "identify the proxy decision maker at some point (ex. when diagnosed as incurable disease or when death is approaching as the disease progresses)" as healthcare providers who identified the proxy decision maker.

Subsequently, we compared preferences about each type of cancer treatment, EOL care, and LST (seven in total) using the chi-square test or Fisher's exact test. Lastly, we conducted multivariate logistic regression analysis of preferences for the seven treatments in each respondent group.

For logistic regression analysis of the general public, we used the following six independent variables based on previous reports and discussion among the authors of this study [15, 21, 22]: gender (reference: male), age <

64 years, education (reference: junior high or high school), living with family, death of a close person in the past 5 years, and presence of a family doctor.

For logistic regression analysis of healthcare providers, we used the following five independent variables based on discussion among the authors: working for $>30$ years, working in hospital, caring for dying patients at least once a month, identifying the proxy decision maker, and participation in a nationwide education program. Probability values were based on two-sided tests and significance was accepted at $p<0.05$. All analyses were conducted using SPSS-J (ver. 24.0; IBM, Tokyo, Japan). 
Table 2 Characteristics of the respondents

\begin{tabular}{|c|c|c|c|c|c|c|}
\hline \multicolumn{7}{|l|}{ General public } \\
\hline & & \multicolumn{5}{|c|}{$\begin{array}{l}\text { General public } \\
(n=973)\end{array}$} \\
\hline & & $n$ & $\%$ & & & \\
\hline \multirow[t]{2}{*}{ Gender } & Male & 535 & 55.0 & & & \\
\hline & Female & 411 & 42.2 & & & \\
\hline \multirow[t]{4}{*}{ Age } & $20-39$ & 148 & 15.2 & & & \\
\hline & $40-64$ & 354 & 36.4 & & & \\
\hline & $65-74$ & 236 & 24.3 & & & \\
\hline & 75- & 212 & 21.8 & & & \\
\hline \multirow[t]{4}{*}{ Education } & Junior high school & 109 & 11.2 & & & \\
\hline & High school & 328 & 33.7 & & & \\
\hline & College & 178 & 18.3 & & & \\
\hline & University/Graduate school & 329 & 33.8 & & & \\
\hline Living with family & Yes & 774 & 79.5 & & & \\
\hline Death of a close person in the past 5 years & Yes & 391 & 40.2 & & & \\
\hline Family doctor & Yes & 403 & 41.4 & & & \\
\hline \multirow[t]{2}{*}{ Healthcare providers } & Physicians ( $n=1039)$ & & Nurses & $=1854)$ & Care & $(n=752)$ \\
\hline & $n$ & $\%$ & $n$ & $\%$ & $n$ & $\%$ \\
\hline \multicolumn{7}{|l|}{ Years of practice } \\
\hline $1-15$ & 139 & 13.4 & 317 & 17.1 & 386 & 51.3 \\
\hline $16-30$ & 392 & 37.7 & 895 & 48.3 & 334 & 44.4 \\
\hline $31-$ & 481 & 46.3 & 612 & 33.0 & 29 & 3.9 \\
\hline \multicolumn{7}{|l|}{ Workplace } \\
\hline Hospital & 652 & 62.8 & 838 & 45.2 & $\mathrm{n} \cdot \mathrm{a}^{\mathrm{b}}$ & $\mathrm{n} \cdot \mathrm{a}^{\mathrm{b}}$ \\
\hline Clinic & 337 & 32.4 & 300 & 16.2 & n. $\mathrm{a}^{\mathrm{b}}$ & $\mathrm{n} \cdot \mathrm{a}^{\mathrm{b}}$ \\
\hline Long-term care facility & $\mathrm{n} \cdot \mathrm{a}^{\mathrm{b}}$ & n. $a^{b}$ & 194 & 10.5 & 340 & 45.2 \\
\hline Care home & $n \cdot a^{b}$ & n. $a^{b}$ & 199 & 10.7 & 396 & 52.7 \\
\hline Visiting nurse office & $\mathrm{n} \cdot \mathrm{a}^{\mathrm{b}}$ & n. $a^{b}$ & 210 & 11.3 & n.a $a^{b}$ & $\mathrm{n} \cdot \mathrm{a}^{\mathrm{b}}$ \\
\hline Other & 10 & 1.0 & 63 & 3.4 & 6 & 0.8 \\
\hline Participation in a nationwide training program & 205 & 19.7 & 164 & 8.8 & 26 & 3.5 \\
\hline \multicolumn{7}{|l|}{ Frequency of caring for dying patients } \\
\hline At least one patient per month & 403 & 38.8 & 549 & 29.6 & 115 & 15.3 \\
\hline One patient per 6-months & 230 & 22.1 & 631 & 34.0 & 349 & 46.4 \\
\hline One patient per year & 131 & 12.6 & 270 & 14.6 & 200 & 26.6 \\
\hline Rarely & 225 & 21.7 & 337 & 18.2 & 72 & 9.6 \\
\hline \multicolumn{7}{|l|}{ EOLD ${ }^{a}$ with patient } \\
\hline To a sufficient extent & 281 & 27.0 & 324 & 17.5 & 139 & 18.5 \\
\hline To some extent & 385 & 37.1 & 809 & 43.6 & 280 & 37.2 \\
\hline Not much. & 135 & 13.0 & 301 & 16.2 & 232 & 30.9 \\
\hline Not involved with dying patients & 196 & 18.9 & 354 & 19.1 & 89 & 11.8 \\
\hline Identifying the proxy decision maker & 830 & 79.9 & 1541 & 83.1 & 597 & 79.4 \\
\hline Sharing documented EOLD ${ }^{a}$ information with the multidisciplinary team & 587 & 56.5 & 969 & 52.3 & 362 & 48.1 \\
\hline
\end{tabular}

a EOLD End-of-life discussion

${ }^{\text {b }}$.a not applicable 


\section{Results}

A total of 973 members of the general public, 1039 physicians, 1854 nurses, and 752 care staff returned the questionnaire (response rates: 16.2, 23.1, 30.9, and 37.6\% respectively). We analyzed all of the returned questionnaires. The characteristics of the respondents are summarized in Table 2. The respondents from the general public included 535 men (55.0\%), and 448 were aged over 65 (46.1\%). Among the healthcare providers, those working for $>31$ years included 481 physicians (47.5\%), 612 nurses (33.6\%), and 29 care staff (3.8\%). The most frequent workplace of doctors and nurses was hospitals [652 (64.4\%) and 838 (45.9\%), respectively], whereas it was long-term care facilities for the elderly in the case of care staff [396 (52.9\%)].

\section{Comparison of the preferences of the general public and recommendations of healthcare providers regarding cancer treatment, EOL care, and LST}

The highest preferences of the general public for cancer treatment, EOL care, and LST were as follows": "Fluid infusion" (48.5\%), "Chemotherapy or radiation" (27.5\%), and "TPN" (13.8\%) (Additional file 1). Similarly, the most common recommendation about cancer treatment, EOL care, and LST made by physicians, nurses, and care staff was "Fluid infusion" (physicians: 59.5\%, nurses: 56.4\%, care staff: 53.6\%) (Additional file 1).

The proportion of the general public who wanted "Chemotherapy or radiation" and "Ventilation" was significantly higher than the level of recommendation by physicians, nurses, and care staff (physicians: $p<0.001$, nurses: $p<0.001$, care staff: $p=0.006$ ) (Fig. 1).

In addition, the proportion of the general public who wanted "CPR" was significantly higher than the level of recommendation by physicians and nurses $(p<0.001)$, although it was significantly lower than that by care staff $(p<0.001)$ (Fig. 1).
Factors related to preferences of the general public and recommendations of healthcare providers with regard to cancer treatment, EOL care, and LST

Multivariate logistic regression analysis revealed that women among the general public had significantly lower preferences for "TPN", "NG tube feeding", and "CPR". In addition, members of the general public over the age of 65 had significantly lower preferences for "TPN", "NG tube feeding", "PEG tube feeding", "Ventilation", and "CPR". Other factors, such as education, living status, death of a close person in the past 5 years, and presence of a family doctor, did not have a significant relationship with preferences for cancer treatment, EOL care, and LST (Tables 3 and 4).

Physicians who had participated in a nationwide training program were significantly less likely to recommend "Fluid infusion", "TPN", "NG tube feeding", and "CPR", whereas those working in hospitals were significantly more likely to recommend "Fluid infusion", "TPN", "NG tube feeding", "PEG tube feeding", and "CPR".

Nurses who cared for at least one dying patient per month were significantly less likely to recommend all seven types of cancer treatment, EOL care, and LST, although nurses working in hospitals were significantly more likely to recommend "Chemotherapy or radiation", "Fluid infusion", and "PEG tube feeding".

The care staff who worked in hospitals were significantly more likely to recommend "Chemotherapy or radiation", "TPN", and "PEG tube feeding", whereas those who cared for at least one dying patient per month were significantly less likely to recommend "CPR" (Tables 3 and 4).

\section{Comparison of the recommendations regarding cancer} treatment, EOL care, and LST among healthcare providers Physicians were more likely to recommend NG tube feeding and PEG tube feeding than nurses, and were

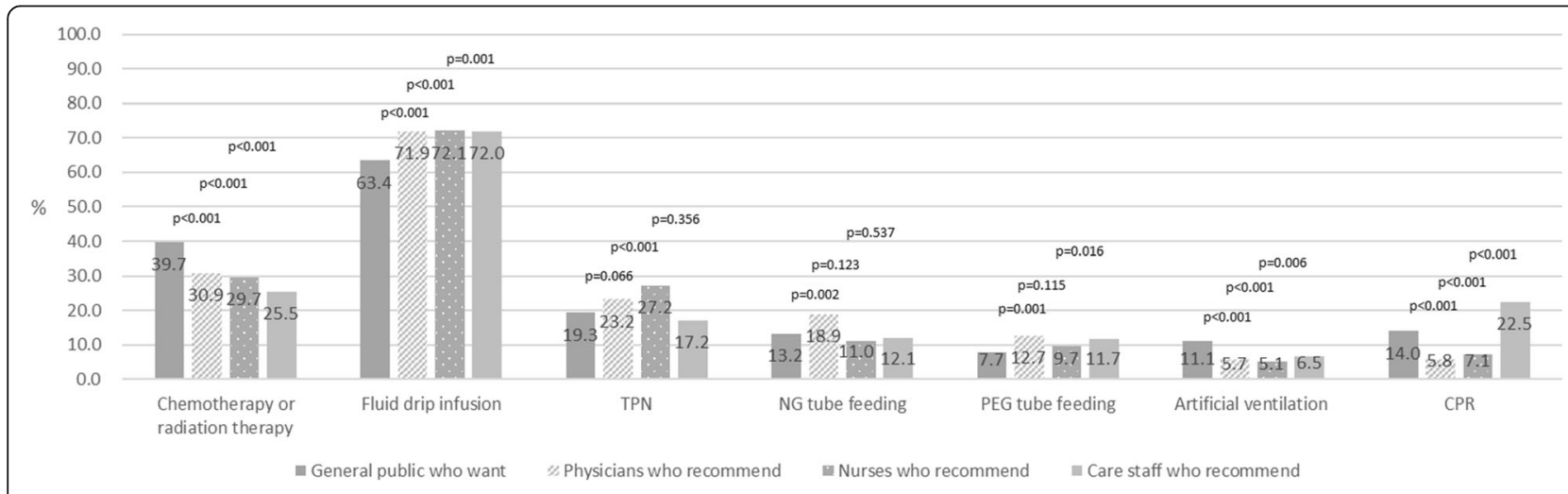

Fig. 1 Comparison of end-of-life treatment and care preferences of the general public with recommendations of healthcare providers. This figure shows the preferences of the general public and recommendations of healthcare providers regarding cancer treatment, EOL care, and LST 


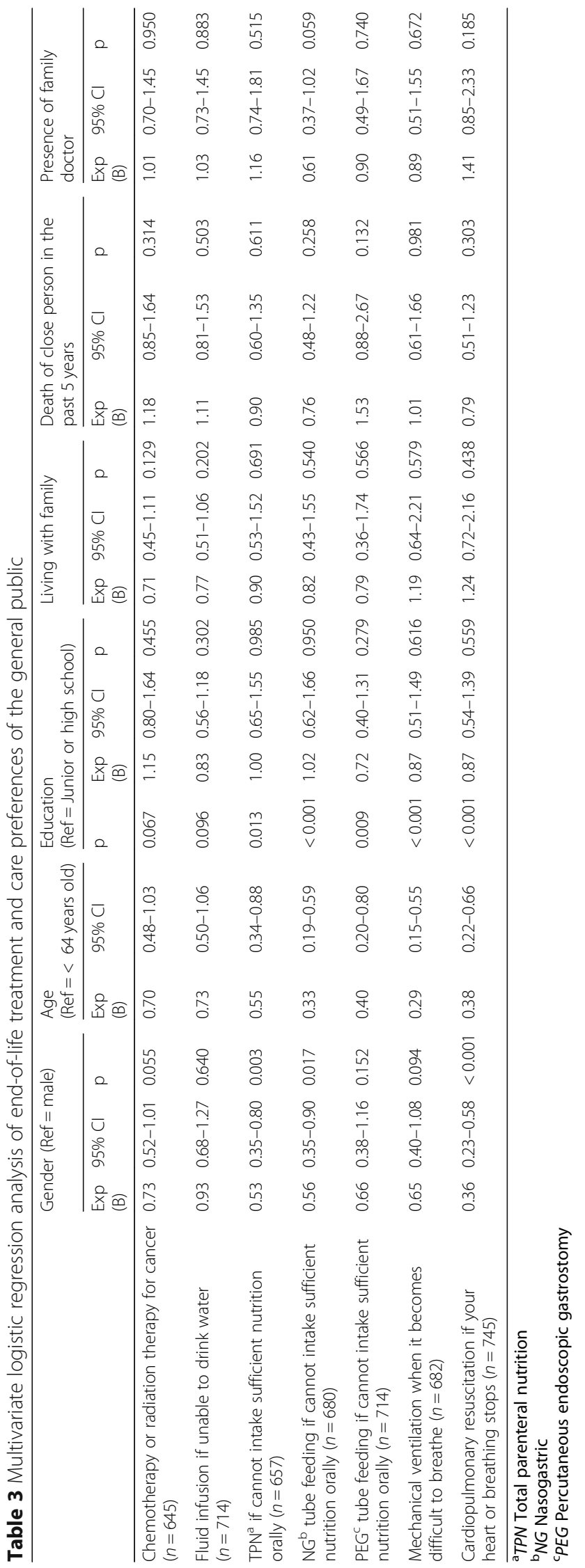




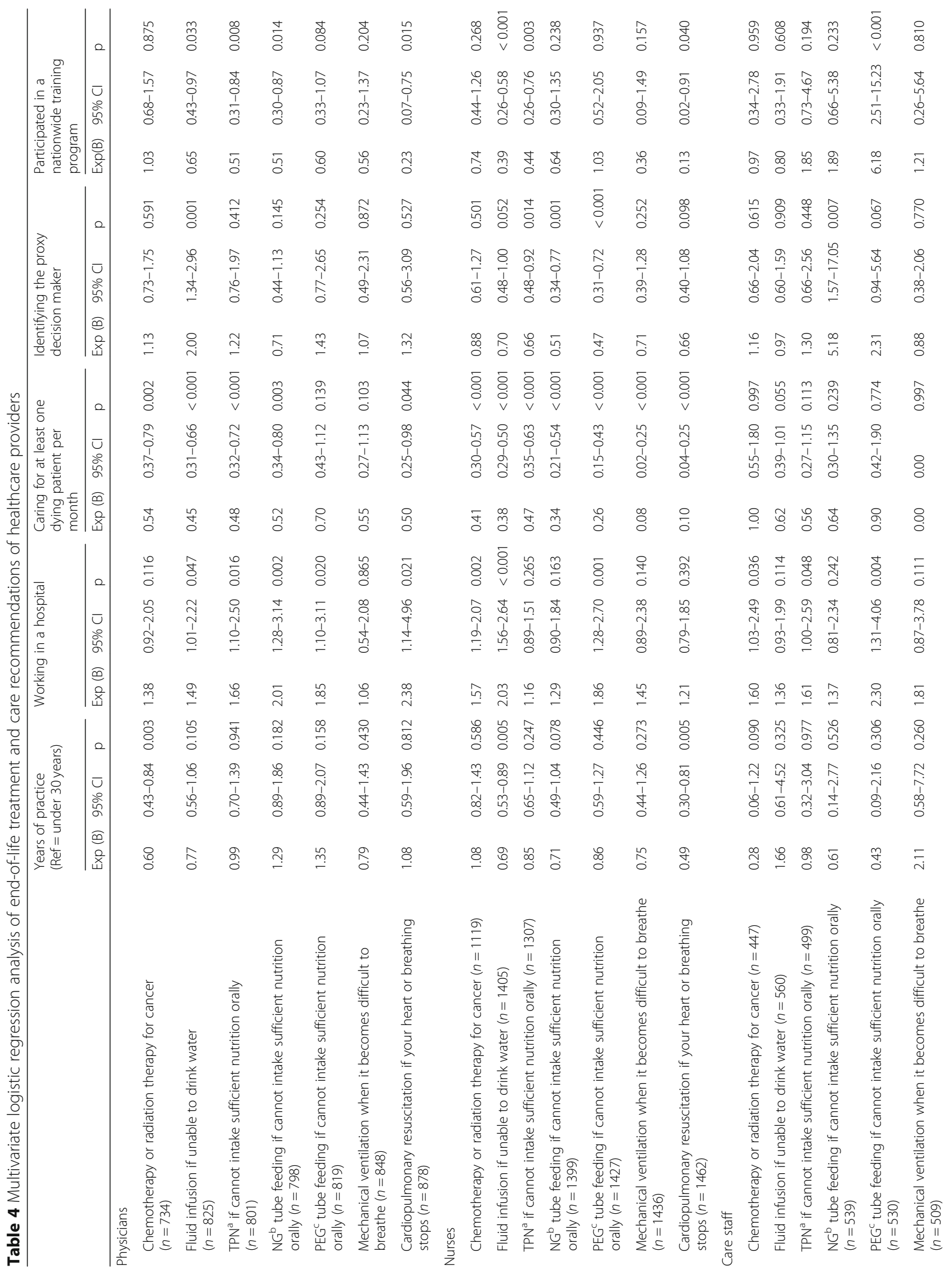




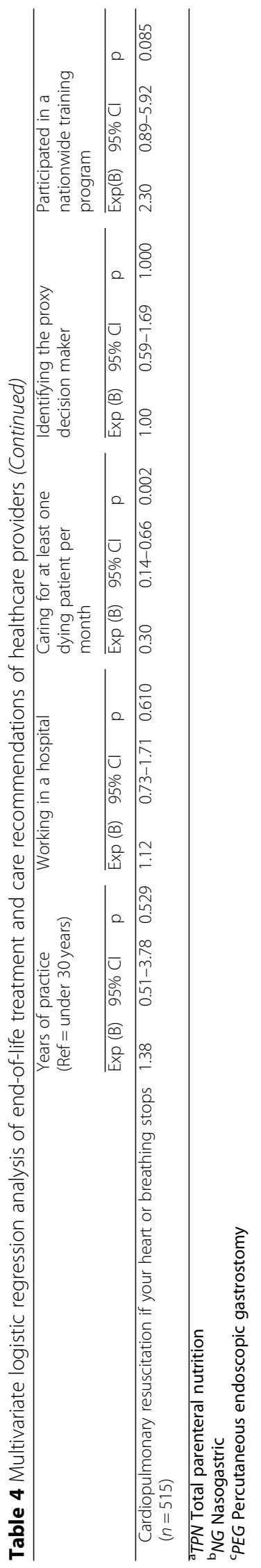


more likely to recommend chemotherapy or radiation therapy, TPN, and NG tube feeding than care staff.

Nurses were more likely to recommend TPN than physicians and care staff. Care staff had a higher rate of recommending $\mathrm{CPR}$ than physicians and nurses (Additional file 2).

\section{Discussion}

This exploratory post-hoc analysis of a population based, cross-sectional anonymous survey in Japan revealed that the general public prefers more aggressive treatment and LST than that recommended by healthcare providers in a hypothetical advanced cancer patient scenario.

The first important finding was that the general public preferred more aggressive treatment and LST than that recommended by the healthcare providers, although CPR was less preferred compared with care staff recommendations. On the other hand, healthcare providers recommended limited medical care, i.e., life-prolonging care that promotes comfort and can be withdrawn, more often than was wanted by the general public [23]. These results suggest some dissonance between patients and healthcare providers with regard to aggressive treatment, LST, and limited medical care, which are considered to be quality indicators for EOL discussion [23-26]. The previous studies demonstrated, the general public has poor knowledge regarding the benefits of aggressive treatment and LST, such as CPR, parenteral nutrition, and hydration, for terminally ill cancer patients $[27,28]$. Therefore, the general public might overestimate the success rate of CPR and the benefit of parenteral nutrition and hydration in late-stage cancer patients. A recent study found that specific information videos and websites regarding LST for the general public, such as the Talk CPR project, which provides knowledge regarding CPR [29], are helpful to reduce the dissonance between the general public and healthcare providers. Such information provision may also encourage patients and caregivers to approach their healthcare provider about this issue.

Our results are consistent with a previous study, which reported that physicians more often misinterpret the wishes of patients who do not want treatment [16]. Thus, healthcare providers should address the expectations of patients with advanced cancer about aggressive treatment, LST, and limited medical care to initiate and facilitate EOL discussion. A recent study suggested that providing specific information through different modalities can improve the confidence and understanding of healthcare providers regarding EOL discussion, and adding such information to existing education programs is considered effective [29].

The second important finding was that the workplace, participation in a nationwide education program on EOL discussion, and experience in EOL care were factors that significantly influenced the recommendations of healthcare providers about EOL care and LST.

Among physicians and nurses, working in a hospital was significantly positively associated with recommending fluid infusion, TPN, NG tube feeding, and PEG tube feeding. On the other hand, participating in a nationwide education program on EOL discussion and sufficient experience in EOL care were significantly negatively associated with recommending fluid infusion, TPN, NG tube feeding, and CPR.

Among the care staff, working at a long-term care facility had a significant positive association with recommending chemotherapy or radiation therapy for cancer, TPN, and PEG tube feeding, whereas having sufficient experience in EOL care had a significant negative association with recommending CPR.

It is difficult to change the workplace, but our study suggested that participation in a nationwide education program on EOL discussion and sufficient experience in EOL care can reduce dissonance regarding nutritional support among physicians, nurses, and patients.

The third important finding of this study was that the recommendations of each type of healthcare provider differed with regard to cancer treatment, EOL care, and LST. There were significant differences regarding the route of nutritional support recommended by physicians, nurses, and care staff, although they all recommended TPN most highly, followed by NG tube feeding and PEG tube feeding. Therefore, there was no major difference in the recommendations about nutritional support, but there were some differences in their preferences depending on the practice environment and individual experience.

Of note, care staff were significantly more likely to recommend CPR than physicians and nurses. This may reflect the anxiety of such staff about a patient dying in front of them, which was recently reported [30].

The fourth important finding was that members of the general public over 65 years old were significantly less likely to prefer NG tube feeding, PEG tube feeding, mechanical ventilation, and CPR. Moreover, female members of the general public were significantly less likely to prefer TPN, NG tube feeding, and CPR. This suggests that the preferences of patients can be inferred based on their demographics.

As this study was an exploratory post-hoc analysis, it has several limitations. First, we did not assess knowledge or beliefs about EOL care that may have influenced the preferences of the general public and the recommendations of healthcare providers about cancer treatment, EOL care, and LST. Second, our study was only conducted in Japan and the response rate was low; therefore, generalization of the results is difficult. Third, as respondents' preparations for EOL care are different, our findings need to be interpreted with caution. 
However, regardless of these limitations, this study provided useful insights into the preferences of the general public and recommendations of healthcare providers with respect to cancer treatment, EOL care, and LST.

\section{Conclusion}

The general public prefers more aggressive treatment and LST than that recommended by the healthcare providers in a hypothetical advanced cancer patient scenario, although the healthcare providers recommended EOL care more than preferred by the general public. Healthcare providers should ask the patient's preference, taking into account that there may be differences between the patient's preference and their recommendations regarding cancer treatment, EOL care, and LST.

\section{Supplementary information}

Supplementary information accompanies this paper at https://doi.org/10. 1186/s12904-020-00546-9.

\section{Additional file 1. Preferences of the general public and} recommendations of healthcare providers regarding EOL care and LST. Number and proportion regarding the preferences of the general public and recommendations of healthcare providers regarding EOL care and LST.

Additional file 2. Comparison of the recommendations regarding cancer treatment, EOL care, and LST among healthcare providers. Number and proportion regarding recommendations for cancer treatment, EOL care, and LST among healthcare providers.

\section{Abbreviations}

CPR: Cardiopulmonary resuscitation; E-FIELD: Education For Implementing End-of-Life Discussion; EOL: End-of-life; LST: Life-sustaining treatment; MHLW: Ministry of Health, Labour and Welfare; NG: Nasogastric; PEACE: Palliative Care Emphasis Program on Symptom Management and Assessment for Continuous Medical Education; PEG: Percutaneous endoscopic gastrostomy; TPN: Total parenteral nutrition

\section{Acknowledgements}

Not applicable.

\section{Authors' contributions}

All authors made substantial contributions to the conception and design of the work. JH and HK facilitated the acquisition of data, TN and HK led the interpretation and drafting of the manuscript, all authors revised it critically, and all authors read and approved the final version.

\section{Funding}

This project received funding from the Health Labour Sciences Research Grant. The funder had no role in the analysis or interpretation of data, the preparation, review, or approval of the manuscript, or the decision to submit the manuscript for publication.

\section{Availability of data and materials}

The datasets used and/or analyzed during the current study are available from the corresponding author on reasonable request.

\section{Ethics approval and consent to participate}

The institutional review board of the University of Tsukuba approved this study. Completion and return of the questionnaire, in combination with the explanatory letter, was considered to indicate voluntary and informed consent to participate.
Consent for publication

Not applicable.

\section{Competing interests}

The authors declare that they have no competing interests.

\section{Author details}

${ }^{1}$ Division of Clinical Medicine, Faculty of Medicine, University of Tsukuba, 1-1-1 Tennoudai, Tsukuba 305-8575, Ibaraki, Japan. ${ }^{2}$ Graduate School of Comprehensive Human Sciences, University of Tsukuba, 1-1-1 Tennoudai, Tsukuba 305-8575, Ibaraki, Japan. ${ }^{3}$ Faculty of Medicine, University of Tsukuba, 1-1-1 Tennoudai, Tsukuba 305-8575, Ibaraki, Japan.

Received: 24 October 2019 Accepted: 17 March 2020

Published online: 24 March 2020

\section{References}

1. Peppercorn JM, Smith TJ, Helft PR, et al. American society of clinical oncology statement: toward individualized care for patients with advanced cancer. J Clin Oncol. 2011;29(6):755-60. https://doi.org/10. 1200/JCO.2010.33.1744.

2. Heyland DK, Barwich D, Pichora D, et al. Failure to engage hospitalized elderly patients and their families in advance care planning. JAMA Intern Med. 2013;173(9):778-87. https://doi.org/10.1001/jamainternmed.2013.180.

3. Wendler D, Rid A. Systematic review: the effect on surrogates of making treatment decisions for others. Ann Intern Med. 2011;154(5):336-46. https:// doi.org/10.7326/0003-4819-154-5-201103010-00008.

4. Silveira MJ, Kim SYH, Langa KM. Advance directives and outcomes of surrogate decision making before death. N Engl J Med. 2010;362(13):1211-8 https://doi.org/10.1056/NEJMsa0907901.

5. Torke AM, Sachs GA, Helft PR, et al. Scope and outcomes of surrogate decision making among hospitalized older adults. JAMA Intern Med. 2014; 174(3):370-7. https://doi.org/10.1001/jamainternmed.2013.13315.

6. Houben CHM, Spruit MA, Groenen MTJ, Wouters EFM, Janssen DJA. Efficacy of advance care planning: a systematic review and meta-analysis. J Am Med Dir Assoc. 2014:15(7):477-89. https://doi.org/10.1016/j.jamda.2014.01.008.

7. Brinkman-Stoppelenburg A, Rietjens JA, van der Heide A. The effects of advance care planning on end-of-life care: a systematic review. Palliat Med. 2014;28(8):1000-25. https://doi.org/10.1177/0269216314526272.

8. Rietjens JAC, Sudore RL, Connolly M, et al. Definition and recommendations for advance care planning: an international consensus supported by the European Association for Palliative Care. Lancet Oncol. 2017;18(9):e543-51. https://doi.org/10.1016/S1470-2045(17)30582-X.

9. Sudore RL, Lum HD, You JJ, et al. Defining advance care planning for adults: a consensus definition from a multidisciplinary delphi panel. J Pain Symptom Manage. 2017;53(5):821-832.e1. https://doi.org/10.1016/j. jpainsymman.2016.12.331.

10. Cardona M, Lewis E, Shanmugam S, et al. Dissonance on perceptions of end-of-life needs between health-care providers and members of the public: quantitative cross-sectional surveys. Australas J Ageing. 2019. https:// doi.org/10.1111/ajag.12630.

11. Yun YH, Kim K-N, Sim J-A, et al. Comparison of attitudes towards five endof-life care interventions (active pain control, withdrawal of futile lifesustaining treatment, passive euthanasia, active euthanasia and physicianassisted suicide): a multicentred cross-sectional survey of Korea. BMJ Open. 2018:8(9):e020519. https://doi.org/10.1136/bmjopen-2017-020519.

12. Tang ST, Chen $\mathrm{CH}$, Wen $\mathrm{F}-\mathrm{H}$, et al. Accurate prognostic awareness facilitates, whereas better quality of life and more anxiety symptoms hinder end-of-life care discussions: a longitudinal survey study in terminally ill Cancer patients' last six months of life. J Pain Symptom Manag. 2018;55(4):1068-76. https:// doi.org/10.1016/j.jpainsymman.2017.12.485.

13. Barrio-Cantalejo IM, Simón-Lorda P, Molina-Ruiz A, et al. Stability over time in the preferences of older persons for life-sustaining treatment. J Bioeth Inq. 2013;10(1):103-14. https://doi.org/10.1007/s11673-012-9417-4

14. Hamano J, Hanari K, Tamiya N. Attitudes and other factors influencing endof-life discussion by physicians, nurses, and care staff: a Nationwide survey in Japan. Am J Hosp Palliat Med. 2019;104990911987656. https://doi.org/10. $1177 / 1049909119876568$

15. Kissane LA, Ikeda B, Akizuki R, Nozaki S, Yoshimura K, Ikegami N. End-of-life preferences of the general public: results from a Japanese national survey. 
Health Policy (New York). 2015;119(11):1472-81. https://doi.org/10.1016/j. healthpol.2015.04.014.

16. Downey L, Au DH, Curtis JR, Engelberg RA. Life-sustaining treatment preferences: matches and mismatches between patients' preferences and clinicians' perceptions. J Pain Symptom Manag. 2013;46(1):9-19. https://doi. org/10.1016/j.jpainsymman.2012.07.002.

17. Yun YH, Han KH, Park S, et al. Attitudes of cancer patients, family caregivers, oncologists and members of the general public toward critical interventions at the end of life of terminally ill patients. Can Med Assoc J. 2011;183(10): E673-9. https://doi.org/10.1503/cmaj.110020.

18. Yamamoto R, Kizawa Y, Nakazawa Y, Morita T. The palliative care knowledge questionnaire for PEACE: reliability and validity of an instrument to measure palliative care knowledge among physicians. J Palliat Med. 2013;16(11): 1423-8. https://doi.org/10.1089/jpm.2013.0112.

19. Nishikawa M, Miura H, Oya S, et al. Feasibility study of a one-day educational program to train advance care planning facilitators (ACPFs) in regional areas. Gan To Kagaku Ryoho. 2016;43(Suppl 1):47-9 http://www. ncbi.nlm.nih.gov/pubmed/28028278. Accessed May 1, 2019.

20. Tsuneto S. Past, present, and future of palliative care in Japan. Jpn J Clin Oncol. 2013;43(1):17-21. https://doi.org/10.1093/jjco/hys188.

21. van Wijmen MPS, Pasman HRW, Widdershoven GAM, Onwuteaka-Philipsen $\mathrm{BD}$. Continuing or forgoing treatment at the end of life? Preferences of the general public and people with an advance directive. J Med Ethics. 2015; 41(8):599-606. https://doi.org/10.1136/medethics-2013-101544.

22. Clarke G, Fistein E, Holland A, Barclay M, Theimann P, Barclay S. Preferences for care towards the end of life when decision-making capacity may be impaired: a large scale cross-sectional survey of public attitudes in Great Britain and the United States. Fuh J-L, ed. PLoS One. 2017;12(4):e0172104. https://doi.org/10.1371/journal.pone.0172104.

23. Kizawa Y, Okada H, Kawahara T, Morita T. Effects of brief nurse advance care planning intervention with visual materials on goal-of-care preference of Japanese elderly patients with chronic disease: A pilot randomized controlled trial. J Palliat Med. 2020.

24. Grunfeld E, Lethbridge L, Dewar R, et al. Towards using administrative databases to measure population-based indicators of quality of end-of-life care: testing the methodology. Palliat Med. 2006;20(8):769-77. https://doi. org/10.1177/0269216306072553.

25. Earle CC, Park ER, Lai B, Weeks JC, Ayanian JZ, Block S. Identifying potential indicators of the quality of end-of-life cancer care from administrative data. J Clin Oncol. 2003;21(6):1133-8. https://doi.org/10.1200/JCO.2003.03.059.

26. Wenger NS, Rosenfeld K. Quality indicators for end-of-life care in vulnerable elders. Ann Intern Med. 2001;135(8 Pt 2):677-85 http://www.ncbi.nlm.nih. gov/pubmed/11601950. Accessed May 6, 2019.

27. Sterpu B, Lindman P, Björkhem-Bergman L. A comparative study on decision and documentation of refraining from resuscitation in two medical home care units in Sweden. BMC Palliat Care. 2019;18(1):80. https://doi.org/ 10.1186/s12904-019-0472-z.

28. Sehatzadeh S. Cardiopulmonary resuscitation in patients with terminal illness: an evidence-based analysis. Ont Health Technol Assess Ser. 2014; 14(15):1-38.

29. Taubert M, Norris J, Edwards S, Snow V, Finlay IG. Talk CPR - a technology project to improve communication in do not attempt cardiopulmonary resuscitation decisions in palliative illness. BMC Palliat Care. 2018;17(1):118. https://doi.org/10.1186/s12904-018-0370-9.

30. Kawakami Y, Hamano J, Kotani M, et al. Recognition of end-of-life care by nursing care staff, and factors impacting their recognition: an exploratory research using mixed methods. Palliat Care Res. 2019;14(1):43-52.

\section{Publisher's Note}

Springer Nature remains neutral with regard to jurisdictional claims in published maps and institutional affiliations.

Ready to submit your research? Choose BMC and benefit from:

- fast, convenient online submission

- thorough peer review by experienced researchers in your field

- rapid publication on acceptance

- support for research data, including large and complex data types

- gold Open Access which fosters wider collaboration and increased citations

- maximum visibility for your research: over $100 \mathrm{M}$ website views per year

At BMC, research is always in progress.

Learn more biomedcentral.com/submissions 